\title{
Types of Work in Forming Analytic and Synthetic Activity Skills in Teaching the Algebra Course
}

\author{
Tatyana Alekseevna Bezusova ${ }^{1}$, Tatyana Vasilyevna Richter ${ }^{{ }^{*}}$, Natalya Yurevna Sugrobova ${ }^{1}$, \\ Larisa Valentinovna Chugainova ${ }^{1}$, Lidiya Gennadievna Shestakova ${ }^{1}$ \\ ${ }^{1}$ Solikamsk State Pedagogical Institute, Perm State National Research University, Solikamsk, RUSSIA
}

Received 26 April 2017 • Revised 19 September 2017 • Accepted 28 September 2017

\begin{abstract}
The relevance of this study is determined by the problem of developing various methods and techniques of analytic and synthetic activity with the aim of finding solutions to problems that involve the use of analysis and synthesis processes. Analytic and synthetic activity plays an important role in the process of cognition. The purpose of the study is to single out types of work aimed at forming analytic and synthetic activity skills in teaching the algebra course. The results of the study: the skills included in the analytic and synthetic activity are distinguished: to dismember the whole into its component parts; to establish relationships between parts of the whole (to distinguish the general and the different, the known and the unknown, the essential and the nonessential); to make up the whole from the parts, a new object from the individual elements; to draw up an action plan for solving the problem (task); to find errors and explain their reasons. Appropriate content-related components are revealed which are required for working with concepts, theorems, and tasks, and should be used to form analytic and synthetic activity skills in schoolchildren when studying algebra. The significance of the study: the materials of the article can be useful for heads of educational structures at various levels, school teachers, gymnasiums, lyceums, and parents.
\end{abstract}

Keywords: teaching algebra in the $7^{\text {th }}$ grade, analytic and synthetic activity of students, analytic and synthetic activity skills, types of work on the formation of analytic and synthetic activity

\section{INTRODUCTION}

Analytic and synthetic activity plays an important role in the process of cognition and is carried out at all its levels; therefore at school, pupils should definitely receive experience of its application. However, educational practice was faced with insufficiently developed questions concerning the types of work on the formation of analytic and synthetic activity skills in the methodical aspect.

G. Aksu, and N. Koruklu (2015), G. Jasečkováand N. Krivoňáková, (2016), A. A. In’am (2016), H. G. Seyhan (2015), A. Walsh (2002), R. W. While (1959) and others were engaged in the development and implementation of instructional technique for the formation of analytic and synthetic activity skills in schoolchildren during the study of mathematics.

The studies of such authors as G. Battilotti (2015), Ö. Sadi, and J. Çakıroğlu (2015), J. Chen, Q. Jiang, Y. Wang, and J. Tang (2016), A. Dhatsuwan and M. Precharattana (2016), K. Gödel (1967) and others are devoted to the problems of the inseparability of analysis and synthesis in the process of studying the laws of objective reality.

The purpose of our study was to identify the types of work aimed at forming analytic and synthetic activity skills in teaching the algebra course.

(C) Authors. Terms and conditions of Creative Commons Attribution 4.0 International (CC BY 4.0) apply. 


\section{Contribution of this paper to the literature}

- The article highlights the skills that are part of the analytic and synthetic activity in teaching the algebra course in order to identify the most effective types of work aimed at their formation.

- To comprehensively form intellectual operations of analysis, synthesis, comparison, which are the basis of analytic and synthetic activity, when working with concepts, theorems, and problems, appropriate content-related components have been identified.

- Also, levels and corresponding criteria and indicators of formedness of the skills that are part of the analytic and synthetic activity.

Achievement of the set goal is conditioned by the solution of the following tasks: to distinguish the skills that are part of the analytic and synthetic activity; to reveal the appropriate content-related components for working with concepts, theorems, and problems that are expedient to use to form the analytic and synthetic activity skills in schoolchildren while studying algebra; to carry out experimental work to identify the levels of formedness for skills that are part of the analytic and synthetic activity.

The research hypothesis is stated as follows: the process of forming the analytic and synthetic activity skills in schoolchildren during the study of algebra will be most effective with the use of focused efforts with concepts, theorems and problems related to the development of basic intellectual operations of analysis and synthesis.

\section{LITERATURE REVIEW}

Various aspects of analytic and synthetic activity are considered in the works of such authors as L. I. Antsyferova (1969), L. S. Vygotsky (1991), Z. I. Kalmykova (1954) and others, who understand this activity as the processes of analysis, synthesis and their combinations. It is emphasized in the studies of I. D. Koldunova (2015), L. N. Landa (1975), O. K. Pivovarkin (2015), N. N. Pospelov (1989), Y. A. Samarin (1962) and other scholars that the processes of comparison are the basis for other intellectual operations and serve as an essential prerequisite for the implementation of analytic and synthetic activity.

The analysis of the studies shows that the development of main intellectual operations of analysis and synthesis is carried out in the conditions of overcoming the unevenness in their formation, establishing correspondences between them, and increasing the development level for each operation (Aksu, and Koruklu, 2015; Sadi, and Çakıroğlu, 2015; Dhatsuwan and Precharattana, 2016; In'am, 2016; Battilotti, 2015; Chen et al., 2016). The works of K. Gödel (1967) are devoted to formally undecidable mathematical judgments.

Analytic and synthetic activity issues in the field of teaching methods for mathematics are covered in the studies of such authors as P. S. Chan (2016), V. A. Dalinger (1995), Sh. N. K. Fazilova (2015), Ya. I. Grudenov (1990), O. B. Episheva and V. I. Krupich (1990), A. A. Korostelev and O. N. Yarygin (2011.), E. V. Epova (2000), N. A. Kazachek and E. V. Epova (2014), P. M. Erdniev and B. P. Erdniev (1986), G. Jasečkováand N. Krivoňáková (2016), H. G. Seyhan (2015), A. Walsh (2002), R. W. While (1959), K. G. Kozhabaev and R. S. Gabdullin (2016), L. I. Tokareva (2014) and others. These scholars considered the main techniques of finding problem solution at school, as well as analysis and synthesis operations in the aspect of their complementarity, use in research activity. In the works of these authors, the problems of teaching pupils about giving proofs, solving problems, organizing generalizedrepeating lessons are raised, various sets of exercises developed by the authors are given that are partially aimed at forming analytic and synthetic activity techniques.

\section{MATERIALS AND METHODS}

The following methods of research were applied:

1) generalization and analysis of the pedagogical experience described in the psychological-pedagogical and methodical literature;

2) statistical processing of quantitative data on the levels of formedness for skills that are part of the analytic and synthetic activity.

To verify the objectivity of the results of the experimental work, the $\chi^{2}$ (chi-square) test was used with the number of degrees of freedom $\mathrm{v}=1$.

The experimental verification of the effectiveness of the types of work presented to form the analytic and synthetic activity skills in schoolchildren was conducted in 2015-2016 and 2016-2017 academic years in algebra classes in grade 7. Participation in this experiment was taken by 25 persons from the reference group (13 boys and 12 girls) and 24 persons from the experimental group (12 boys and 12 girls) who had agreed to the study. 
Table 1. Purpose and content of the experimental work stages

\begin{tabular}{lll}
\hline Stage & Purpose & Content \\
\hline $\begin{array}{l}\text { Ascertaining assessment } \\
\text { of school students }\end{array}$ & $\begin{array}{l}\text { Identification of the initial level of formedness of skills that } \\
\text { are part of the analytic and synthetic activity of } \\
\text { schoolchildren }\end{array}$ & Test paper \\
\hline Forming stage & $\begin{array}{l}\text { Formation of the skills that make up the analytic and } \\
\text { synthetic activity of schoolchildren }\end{array}$ & $\begin{array}{l}\text { Use of the selected types of work on } \\
\text { the formation of analytic and synthetic } \\
\text { activity skills in algebra lessons }\end{array}$ \\
\hline $\begin{array}{l}\text { Control assessment of } \\
\text { school students }\end{array}$ & $\begin{array}{l}\text { Identification of the initial level of formedness of skills that } \\
\text { are part of the analytic and synthetic activity of } \\
\text { schoolchildren }\end{array}$ & Test paper \\
\hline
\end{tabular}

Table 2. Examples of assignments for the ascertaining assessment of school students

\begin{tabular}{|c|c|}
\hline Problem type & Example \\
\hline $\begin{array}{l}\text { Dismemberment of the whole } \\
\text { problems }\end{array}$ & How many ways can you find to divide a square into four identical parts? \\
\hline $\begin{array}{l}\text { nent of relationships } \\
\text { parts of the whole }\end{array}$ & $\begin{array}{l}\text { There are } 5 \mathrm{~A} \text { grade, } 20 \text { B grade and } 10 \mathrm{C} \text { grade pupils in a class. An A grade pupil can get only } \\
5 \text { for an answer, a B grade pupil can get } 4 \text { or } 5, \text { a C grade pupil can get } 3,4, \text { or } 5 \text {. The inspector } \\
\text { came to the class; he does not know any of the students. How many people it is enough for } \\
\text { him to call to the board, so that at least one excellent grade is sure to be given? }\end{array}$ \\
\hline Integration by parts problems & $\begin{array}{l}\text { Only } 4 \text { people can sit simultaneously at a square table, one on each side; } 33 \text { of these tables } \\
\text { were placed in a row (close to each other). How many people can sit at the resulting long table? }\end{array}$ \\
\hline Solution planning problems & $\begin{array}{l}\text { It took only } 1392 \text { figures to number the pages of a book. How many pages are there in this } \\
\text { book? }\end{array}$ \\
\hline $\begin{array}{l}\text { rror finding problems and } \\
\text { xplanation of the error reason }\end{array}$ & $\begin{array}{l}\text { In one of the } 2 \text { riser blocks of flats in a sixteen-storey house there are apartments numbered } 65 \text {, } \\
66,67 \text {, and } 68 \text { on the first floor ( } 4 \text { apartments on each storey landing). In what riser blocks of } \\
\text { flats and on which floor is the apartment numbered } 265 \text { located? }\end{array}$ \\
\hline
\end{tabular}

The fundamental requirement for the reference group sampling was that at the stage of ascertaining assessment of school students, their results were not lower than those of the experimental one. The experiment was conducted by teachers of the highest category, who have taught children in school for more than 20 years.

The work consisted of three stages: the ascertaining assessment of school students, the forming stage, and the control assessment, the purposes and content of which are given in Table 1.

At the first stage, the schoolchildren were asked to perform 10 tasks, checking the formedness of the skills that make up the analytic and synthetic activity ( 2 tasks per each skill), the methodology proposed by L. V. Bochkareva (2014) was used, adapted to the process of teaching algebra in school. Examples of tasks are presented in Table 2.

The levels and corresponding criteria and indicators of the formedness of the skills that are part of the analytic and synthetic activity were also highlighted (Table 3 ).

Each task was evaluated on a 2.5-point scale, then the results were summarized and conclusions were made about the level of formedness of the skills that make up the analytic and synthetic activity: low - level ranging from 0 to 9 points inclusive, medium - level from 10 to 17 points inclusive, and high level - from 18 up to 25 points. All calculations were carried out using the MS Excel spreadsheet. It was proposed to solve similar 10 assignments during the control assessment of school students. 
Table 3. Levels, criteria and indicators of formedness for skills that are part of the analytic and synthetic activity

\begin{tabular}{|c|c|c|c|}
\hline \multirow{2}{*}{ Criteria } & Low level & Medium level & High level \\
\hline & \multicolumn{3}{|c|}{ Indicators } \\
\hline $\begin{array}{l}\text { Ability to } \\
\text { dismember the } \\
\text { whole into its } \\
\text { component parts }\end{array}$ & $\begin{array}{l}\text { - distinguishing components in the } \\
\text { problem situation; } \\
\text { - distinguishing the processes in } \\
\text { which the components are }\end{array}$ & $\begin{array}{l}\text { - seeing the object structure; } \\
\text { - distinguishing numerical } \\
\text { characteristics of the components } \\
\text { and processes. }\end{array}$ & $\begin{array}{l}\text { - possessing the 'structural vision of } \\
\text { the object'; } \\
\text { - finding non-standard ways to solve } \\
\text { the problem. }\end{array}$ \\
\hline $\begin{array}{l}\text { Ability to } \\
\text { establish } \\
\text { relationships } \\
\text { between parts of } \\
\text { the whole }\end{array}$ & $\begin{array}{l}\text { - finding dependencies between } \\
\text { the components; } \\
\text { - expressing some values through } \\
\text { others. }\end{array}$ & $\begin{array}{l}\text { - identifying significant data } \\
\text { relationships in the problem } \\
\text { situation; } \\
\text { - searching for new data through } \\
\text { the correlation of the problem } \\
\text { situation with its requirements. }\end{array}$ & $\begin{array}{l}\text { - identifying features (properties and } \\
\text { relationships) mentally in the objects } \\
\text { under consideration; } \\
\text { - creating fundamentally new } \\
\text { approaches to the solution of the } \\
\text { problem. }\end{array}$ \\
\hline $\begin{array}{l}\text { Ability to make } \\
\text { up the whole } \\
\text { from the parts }\end{array}$ & $\begin{array}{c}\text { - identifying common and } \\
\text { distinctive features in the objects, } \\
\text { and the relationships between } \\
\text { them; } \\
\text { - finding similarities between the } \\
\text { objects; } \\
\text { - forming connections. }\end{array}$ & $\begin{array}{l}\text {-finding analogies; } \\
\text { - making generalization; } \\
\text { - connecting knowledge } \\
\quad \text { components; } \\
\text { - formulating conclusions } \\
\text { independently. }\end{array}$ & $\begin{array}{l}\text { - connecting abstract concepts with } \\
\text { particular ones; } \\
\text { - operating with fuzzy concepts; } \\
\text { - showing a creative approach to } \\
\text { solving problems. }\end{array}$ \\
\hline $\begin{array}{l}\text { Ability to draw } \\
\text { an action plan } \\
\text { for problem } \\
\text { solving }\end{array}$ & $\begin{array}{l}\text { - demonstrating the understanding } \\
\text { of the problem; } \\
\text { - demonstrating the understanding } \\
\text { of the sequence of actions to solve } \\
\text { the problem; } \\
\text { - generating an idea of the } \\
\text { expected outcome of the problem } \\
\text { solution; } \\
\text { - planning activities to solve the } \\
\text { problem. }\end{array}$ & $\begin{array}{l}\text { - formulating the problem with the } \\
\text { help of a teacher; } \\
\text { - having ideas about methods of } \\
\text { problem solving; } \\
\text { - seeing the expected result; } \\
\text { - making analysis of the problem } \\
\text { situation; } \\
\text { - making analysis of the problem } \\
\text { solving process. }\end{array}$ & $\begin{array}{l}\text { - formulating and analyzing the } \\
\text { problem independently; } \\
\text { - defining a plan for solving the } \\
\text { problem; } \\
\text { - making analysis of the problem } \\
\text { solving methods; } \\
\text { - making an objective analysis of the } \\
\text { results of solving the problem. }\end{array}$ \\
\hline $\begin{array}{l}\text { Ability to find } \\
\text { errors and } \\
\text { explain their } \\
\text { reasons }\end{array}$ & $\begin{array}{l}\text { - adducing arguments that confirm } \\
\text { availability of errors; } \\
\text { - presenting facts explaining the } \\
\text { reasons of the errors. }\end{array}$ & $\begin{array}{c}\text { - evaluating the results obtained in } \\
\text { accordance with the available } \\
\text { errors; } \\
\text { - identifying the nonessential } \\
\text { moments. }\end{array}$ & $\begin{array}{l}\text { - suggesting ways to eliminate } \\
\text { errors; } \\
\text { - making analysis of the work results } \\
\text { on the reasons of errors. }\end{array}$ \\
\hline
\end{tabular}

\section{RESULTS}

Based on the generalization and analysis of the pedagogical experience described in the psychologicalpedagogical and methodical literature, the skills that make up the analytic and synthetic activity are singled out:

- dismembering the whole into its component parts;

- establishing relationships between parts of the whole (distinguishing between the general and the different, the known and the unknown, the essential and the nonessential);

- integrating the whole from the parts, making a new object from the individual elements;

- drawing up an action plan to solve the problem (tasks);

- finding errors and explaining their reasons.

The following types of work and their content-related components are distinguished to form analytic and synthetic activity skills in students in the process of teaching algebra:

\section{Formation of Ideas about Analysis, Synthesis, and Comparison Techniques}

The following theoretical material is included in the content under consideration:

- analysis as a general logical method of mental activity, its application and significance in human life;

- types and forms of analysis (dismemberment of the whole into its component parts, establishment of relationships between the parts of the whole, analysis as the basis for classifying items, retrospective analysis);

- ways to establish relationships between the parts of the whole; 


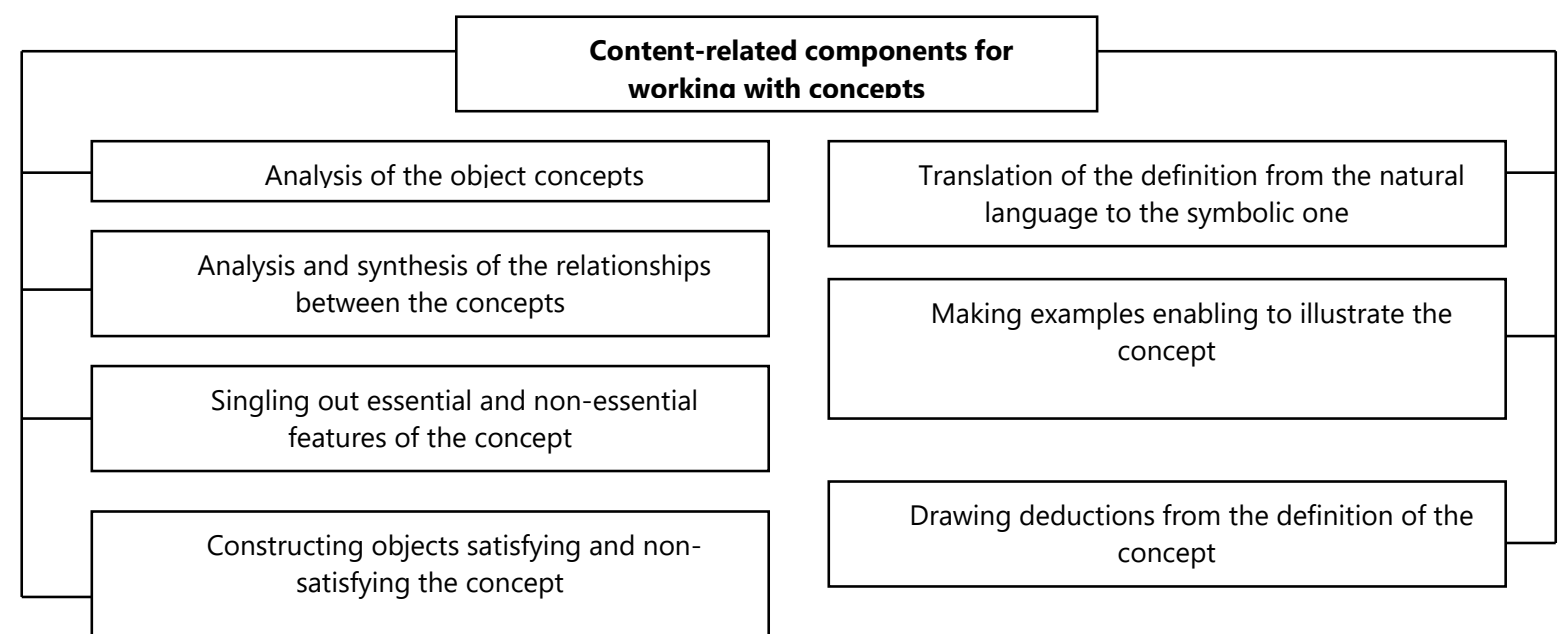

Figure 1. Content-related components for working with concepts

- the essence of retrospective analysis;

- synthesis as a general logical method of mental activity, its application and significance in human life;

- types and forms of synthesis (synthesis as a result of analysis, anticipating synthesis);

- mathematical sophisms, logical tasks.

It is advisable to include this material in the topic "Elements of Logic", informing students about the nature of techniques for analytic and synthetic activity, the feasibility of their application in different situations.

The place of study for the listed contents depends on the textbook chosen by the teacher. It is more convenient to do this in the $7^{\text {th }}$ grade, since it is in this time interval that the concepts of an axiom, a theorem, a proof from the opposite, a hypothesis are formed in schoolchildren.

\section{Working with Concepts}

Working with concepts and their definitions has a significant potential for the successful formation of analytic and synthetic activity skills in schoolchildren at algebra lessons, primarily such as the dismemberment of the whole into parts and the establishment of relationships between parts of the whole by distinguishing the general and the different, the essential and the nonessential. It is advisable to include methods of observation and simulation, exercises for identification of the generic concept and generic difference, independent construction of definitions, their verification, error correction, drawing up the 'pedigree' of the concept, conducting the classification in the work with the learners.

It is important to study the essence of the definition, its types and rules of construction, essential and nonessential features, characteristic properties based on the material of mathematical concepts.

Figure 1 shows the content-related components for working with concepts that should be appropriately used to form the analytic and synthetic activity skills in schoolchildren in the study of algebra.

\section{Working with Theorems}

The theorem should be regarded as teaching the analysis of ready-made reasoning, their reproduction, independent discovery of the fact, search and construction of proofs, and also refutation of the proposed reasoning. The types of tasks can include:

- the dismemberment of the whole into parts, the establishment of relationships between parts of the whole; for example, "single out the condition and conclusion of the theorem", "single out the stages in the proposed proof", "draw up a plan for the proposed proof of the theorem", etc.;

- the integration of the whole from the parts; for example, "restore the formulation of the theorem according to the proposed fragments", select statements that make up the formulation of the theorem from the proposed ones", etc.;

- drawing up an action plan; for example, "the formulation of the theorem is given; draw up an action plan to prove it"; 


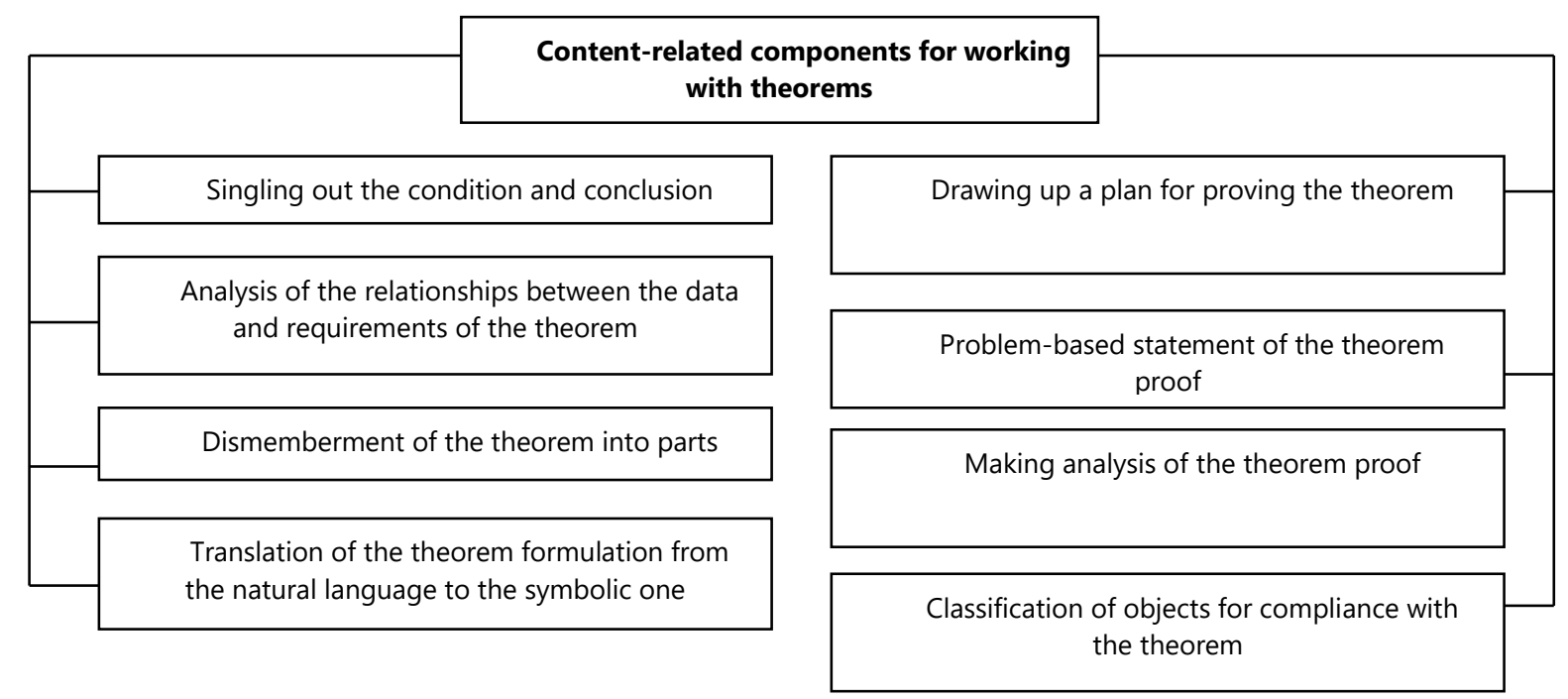

Figure 2. Content-related components for working with theorems

- verification of the proof, correction of errors.

Figure 2 shows the content-related components for working with theorems that are useful to form the analytic and synthetic activity skills in schoolchildren while teaching algebra.

\section{Working with Problems}

The following types of work should be envisaged:

First, students should be taught to analyze the text of the problem at the first stage. To do this, the student should have a good understanding of three main questions that are asked at the first stage (What is the task about? What is to be found? What is given?), and also the general requirements for their answers. To work out the skills to ask questions and answer them correctly, it is possible to organize work with several problems (without solving them), during which the teacher first shows how it can be done, and then the schoolchildren try to do the same work themselves with a mandatory test of the result.

Secondly, students should be taught to find a way to solve the problem. As in the first case, students need to be acquainted with the basic methods of search (moving from condition to conclusion, moving from conclusion to condition, moving from two sides, imperfect analysis) and organize work on their assimilation. This can be done using a combination of the following forms of organization of learning activities: the search for a solution method with the entire class, with one student (when the class checks), and independent search (with mandatory verification of the correctness of the questions posed).

Third, the analytic and synthetic activity skills are actively formed at the last stage of working with a problem, where it is required to analyze the solution obtained, check the result, generalize the solution method, and so on. A final, retrospective analysis of the solution should play a special role here in order to identify and assimilate the general methods of reasoning used in the process of solving the problem.

Fourth, analysis and synthesis, on the one hand, are at the heart of model simulation and transformation actions. On the other hand, the use of simulation actions contributes to the further development of analytic and synthetic activities in schoolchildren. As it is easily noticed, these actions will be formed at the stage of translating the text of the problem into the language of models (short entry, diagram, table, figure, numerical expression, equation) and vice versa (compilation using the text model). Solving geometric problems by coordinate, vector and other methods is aimed at the development of the action to transform the model (its analysis and synthesis). Mathematical models, being a meta-subject content, are used in studying other educational subjects.

In the process of working with mathematical problems, it is necessary to practice the notion of analyzing the text of the problem (requirements for its representation in the form of a short entry, a table), techniques for finding the solution method (moving from condition to conclusion, from conclusion to condition, imperfect analysis).

Figure 3 shows the content-related components for the solution of problems that are advisable to use in forming the analytic and synthetic activity skills in schoolchildren while teaching algebra. 


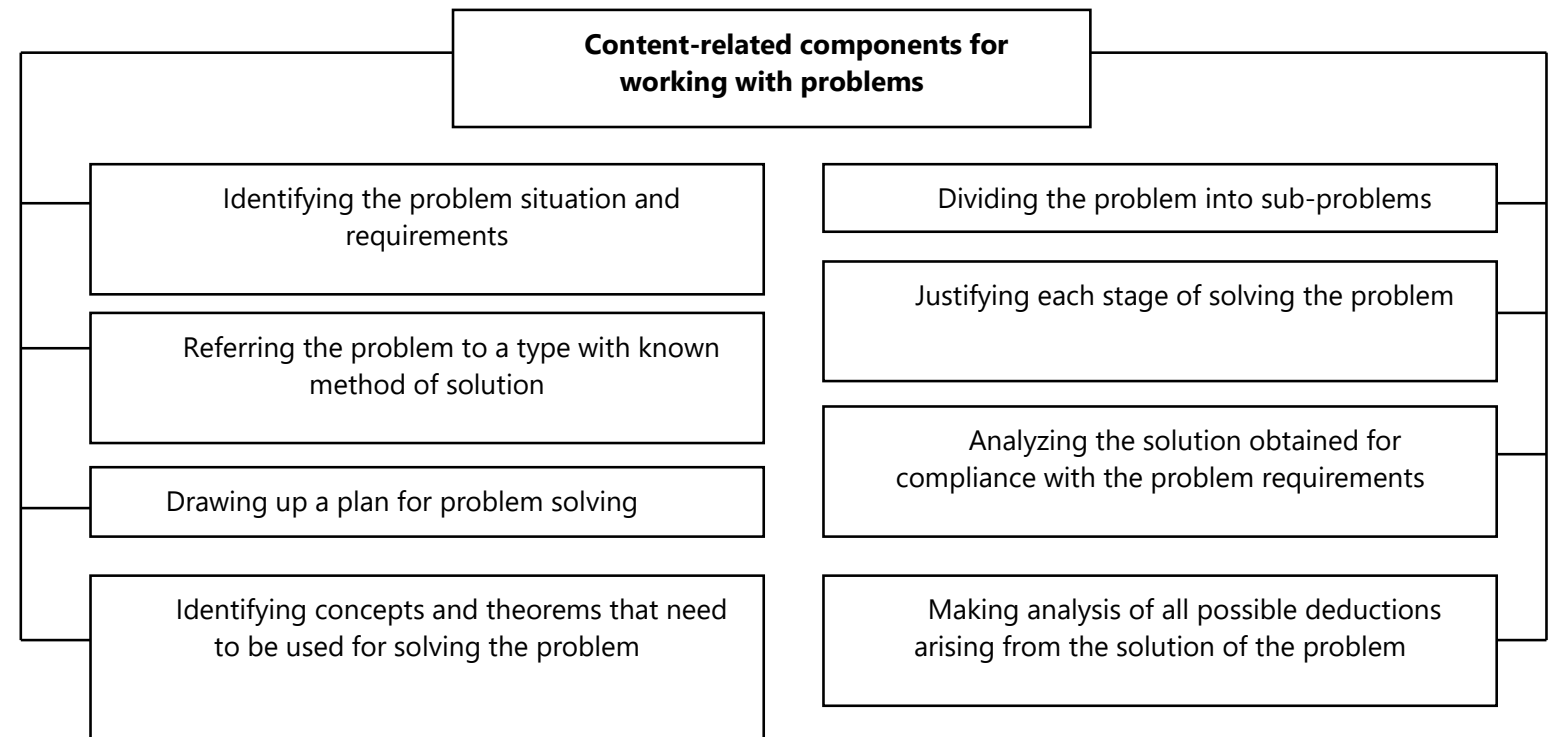

Figure 3. Content-related components for working with problems

\begin{tabular}{|c|c|}
\hline Types of work \\
Fynthesis, and methods of comparison
\end{tabular}

Figure 4. The influence of the types of work on the formation of analytic and synthetic activity skills

Table 4. Results of ascertaining and control assessment of school students

\begin{tabular}{|c|c|c|c|c|c|}
\hline & & \multicolumn{2}{|c|}{$\begin{array}{l}\text { 2015-2016 academic year (ascertaining } \\
\text { assessment of school students) }\end{array}$} & \multicolumn{2}{|c|}{$\begin{array}{c}\text { 2016-2017 academic year (control assessment } \\
\text { of school students) }\end{array}$} \\
\hline & & Experimental group & Reference group & Experimental group & Reference group \\
\hline \multirow{2}{*}{ Low } & $\%$ & 72 & 75 & 12 & 41.67 \\
\hline & persons & 18 & 18 & 3 & 10 \\
\hline \multirow{2}{*}{ Medium } & $\%$ & 28 & 25 & 68 & 58.33 \\
\hline & persons & 7 & 6 & 17 & 14 \\
\hline \multirow{2}{*}{ High } & $\%$ & 0 & 0 & 20 & 0 \\
\hline & persons & 0 & 0 & 5 & 0 \\
\hline
\end{tabular}

Figure 4 shows the influence of the identified types of work on the formation of the analytic and synthetic activity skills in schoolchildren during the study of algebra.

In the process of statistical processing of quantitative data on the levels of formedness for skills that make up the analytic and synthetic activity, the following results were obtained (Table 4).

Let us illustrate the obtained results by a diagram in \% for visual clarity (Figures 5, 6). 


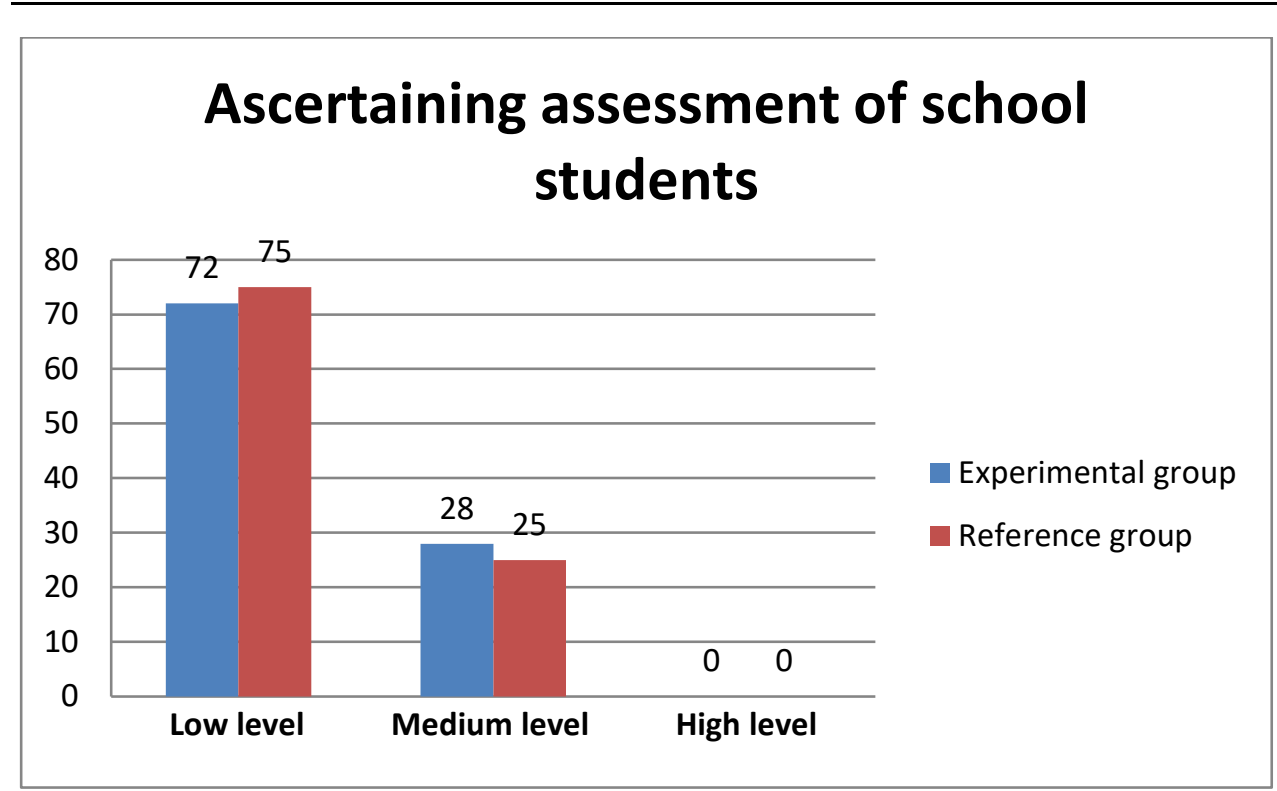

Figure 5. Results of the ascertaining assessment of school students

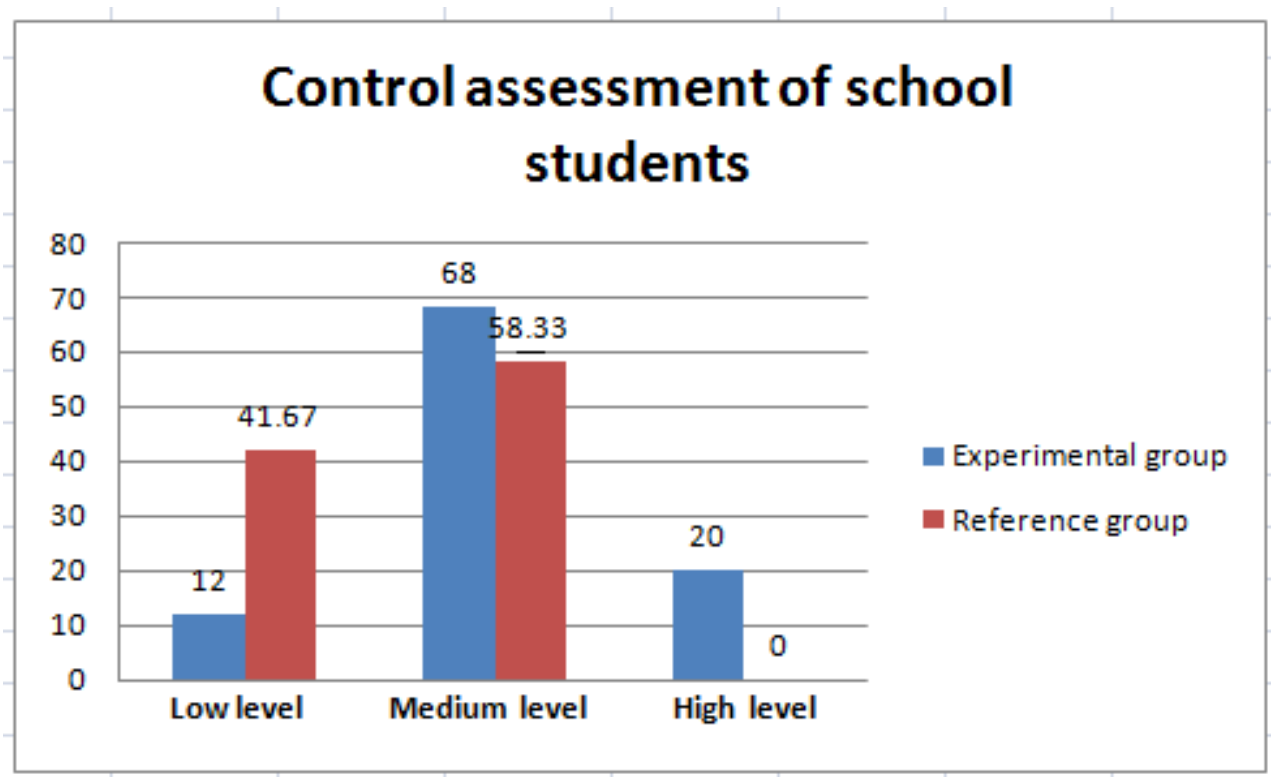

Figure 6. Results of control assessment of school students

Table 5. Change in the level of formedness for the analytic and synthetic activity skills

\begin{tabular}{ccc}
\hline & \multicolumn{2}{c}{ Change in the level of formedness for the analytic and synthetic activity skills } \\
\cline { 2 - 3 } & Experimental group & Reference group \\
\hline Low, \% & $\downarrow$ by 60 & $\downarrow$ by 33.33 \\
\hline Medium, \% & $\uparrow$ by 40 & $\uparrow$ by 33.33 \\
\hline High, $\%$ & $\uparrow$ by 20 & Without changes \\
\hline
\end{tabular}

Changes in the level of formedness of schoolchildren's skills that make up the analytic and synthetic activity are given in Table 5 .

As shown by the assessment results, formedness of students' analytic and synthetic activity skills increased, though it did not reach the maximum level. This is explained by the fact that the process of forming the chosen skills is long and, due to the age characteristics of the school students, is not completed, but will continue in the future.

Comparison of the students' results in the reference and experimental groups confirms the effectiveness of the work done. 
To verify the objectivity of the results of the experimental work, the criterion $\chi^{2}$ (chi-square) was used. The authors hypothesized that the difference in the data in the samples (experimental and reference groups) is explained by random causes.

According to the table of critical statistic values having the distribution of $\chi^{2}$ (chi-square) for the significance level $\mathrm{a}=0.05$ and the number of degrees of freedom $\mathrm{v}=\mathrm{c}-1=1$, where $\mathrm{c}$ is the number of levels, $\mathrm{T}_{\text {crit }}=3.841$ (since the number of schoolchildren having high level of the analytic and synthetic activity skills formedness is zero, the number of levels was taken as $\mathrm{c}=2$ ). $\mathrm{T}_{\mathrm{obs}}=0.763$.

Since $\mathrm{T}_{\mathrm{obs}}<\mathrm{Tc}_{\mathrm{rit}}$, then according to the rule of decision-making, there are no grounds to reject the hypothesis, i.e. the difference in the level of formedness for analytic and synthetic skills activity in schoolchildren in experimental and reference groups is determined by random factors.

Thus, the conclusions drawn confirm the hypothesis that the process of forming the analytic and synthetic activity skills in schoolchildren while studying algebra will be most effective in case of focused efforts in working with concepts, theorems and problems associated with the development of basic intellectual operations of analysis and synthesis.

\section{DISCUSSION}

As a result of the research, content-related components for working with concepts, theorems, and problems were identified, which are advisable for use to form the analytic and synthetic activity skills in schoolchildren when studying algebra:

- when working with concepts: analyzing the object concepts, carrying out analysis and synthesis of the relationships between the objects of the concept, identifying the essential and nonessential features of the concept, constructing objects that satisfy and do not satisfy the concept, translating the definition from the natural language to the symbolic one, making examples that illustrate the concept, drawing deductions from the definition of the concept;

- when working with theorems: singling out the condition and conclusion of the theorem, analyzing the relationships between the data and the requirements of the theorem, dismembering the theorem into parts, translating the theorem formulation from the natural language to the symbolic one, drawing up a plan for proving the theorem, making a problem-based statement of the theorem proof, making analysis of the theorem proof, classifying objects for compliance with the theorem;

- when working with problems: identifying the problem situation and requirements, referring the problem to a type with a known method of solution, drawing up a plan for solving the problem, identifying concepts and theorems that need to be used for solving the problem, dividing the problem into sub-problems, justifying each stage of solving the problem, analyzing the solution obtained for compliance with the problem requirements, making analysis of all possible deductions arising from the solution of the problem.

The results of the research can be used by educators-researchers to develop scientific substantiations and methodological recommendations on the formation of analytic and synthetic activity skills not only for schoolchildren, but also for university students, as well as for practitioners in the educational process.

In general, it is possible to speak of a positive trend in the formation of the considered analytic and synthetic activity skills in the school students, with the help of the selected content and types of work. In the process of experimental work, it was revealed that the described materials and types of work are effective.

\section{CONCLUSION}

The following tasks were posed in the study: to identify the skills that are part of the analytic and synthetic activity; to identify content-related components for work with concepts, theorems, and problems that are appropriate to use while forming the analytic and synthetic activity skills in schoolchildren in the study of algebra; to carry out experimental work to identify the levels of formedness for analytic and synthetic activity skills.

As a result of the work carried out, the skills that are part of the analytic and synthetic activity were singled out, including the ability to dismember the whole into its component parts; to establish relationships between parts of the whole to distinguish the general and the different, the known and the unknown, the essential and the nonessential; to make up the whole from the parts, a new object from the individual elements; to draw up an action plan for solving the problem (task); to find errors and explain their reasons.

When working with mathematical concepts, it is advisable to include methods of observation and simulation, exercises for identification of the generic concept and generic difference, independent construction of definitions, their verification, error correction, drawing up the 'pedigree' of the concept, conducting the classification. When working with the theorem, it is necessary to use tasks for dismemberment of the whole parts, establishment of 
relationships between parts of the whole, integration of the whole from the parts, drawing up of an action plan, verification of proofs, and correction of errors. When working with the problem, it is necessary to analyze the text of the task at the first stage, to carry out training in finding a way to solve it, to develop the analytic and synthetic activity skills at the last stage of working with the problem, to use simulation elements.

Working with the concepts and notions of analysis, synthesis and comparison techniques most effectively influence the formation of such analytic and synthetic activity skills as the dismemberment of the whole into parts and the establishment of relationships between parts of the whole, whereas working with theorems and problems has an impact on drawing up a plan for solving the problem and finding an error, which is explained by the structure of the corresponding type of work.

It should be noted that focused efforts in formation of techniques for analytic and synthetic activity in schoolchildren in the process of teaching mathematics has a positive effect on the formation of logical and mathematical thinking in them, and the ability to use the obtained knowledge in various situations and on various subject content.

The results of experimental verification of the presented content and types of works for the formation of the analytic and synthetic activity skills in schoolchildren while teaching algebra have proven their effectiveness.

Directions of further research are related to the identification of analytic and synthetic activity skills in students of higher educational institutions.

\section{ACKNOWLEDGEMENTS}

This study was carried out within the framework of a fundamental research on the topic "Research of interactive methods of educational interaction as a factor in the formation of professional competencies of students".

\section{REFERENCES}

Aksu, G., \& Koruklu, N. (2015). Determination the effects of vocational high school students' logical and critical thinking skills on mathematics success. Egitim Arastirmalari- Eurasian Journal of Educational Research, 59, 181206. doi:10.14689/ejer.2015.59.11

Antsyferova, L. I. (1969). The principle of the connection between consciousness and activity and the methodology of psychology. Methodological and Theoretical Problems of Psychology. Moscow: Nauka,

Bakirov, R. F. (2016). Analytic-synthetic ability and ways of its development in schoolchildren. International Journal of Humanitarian and Natural Sciences, 1(3), 76-80.

Battilotti, G. (2015). Symmetry vs. duality in logic: An interpretation of Bi-logic to model cognitive processes beyond inference. International Journal of Cognitive Informatics and Natural Intelligence, 8(4), 83-97. doi:10.4018/ijcini.2014100105

Bochkareva, L. V. (2014). Development of analysis, synthesis and foresight in the process of solving problems in probability theory: Textbook. Allowance. Ishim.

Chan, P. S. (2016). From passive to active learning in A-level mathematics classroom. Proceeding of the 12th International Conference of the Learning Sciences: Transforming Learning, Empowering Learners, ICLS; National Institute of Education (NIE), Nanyang Technological University Singapore; Singapore; 20 June 2016-24 June 2016, 2, 1302-130.

Chen, J., Jiang, Q., Wang, Y., \& Tang, J. (2016). Study of data analysis model based on big data technology. IEEE International Conference on Big Data Analysis, ICBDA, Hangzhou, China. doi:10.1109/ICBDA.2016.7509810

Dalinger, V. A. (1995). Methods of work on the formulation, proof and consolidation of the theorem: A book for teachers. Omsk.

Dhatsuwan, A., \& Precharattana, M. (2016). BLOCKYLAND: A Cellular Automata-Based Game to Enhance Logical Thinking. Simulation and Gaming, 47(4), 445-464. doi:101177/1046878116643468

Episheva, O. B., \& Krupich, V. I. (1990). Teach students to study mathematics: the formation of methods of educational activity: a book for the teacher. Moscow: Obrazovanie.

Epova, E. V. (2000). Formation of analytic and synthetic activity in students of pedagogical universities when studying the course of algebra and theory of numbers. Candidate Thesis (Education). Novosibirsk.

Erdniev, P. M, \& Erdniev, B. P. (1986). Integration of didactic units in teaching mathematics: A book for teachers. Moscow: Obrazovanie.

Fazilova, Sh. N. K. (2015). Solution of mathematical problems, as a way of development of logical thinking of pupils of primary classes. The World of Science, Culture, Education, 3, 178-181. 
Gödel, K. (1967). On formally undecidable propositions of Principia Mathematica and related systems. In Heijenoort J. From Frege to Gödel: A source book in mathematic logic, 1879 - 1931. Cambridge, Mass: Harvard University Press. XII, pp. 596-616.

Grudenov, Ya. I. (1990). Perfection of the methodology of the teacher of mathematics: a book for the teacher. Moscow: Obrazovanie.

In'am, A. A. (2016). Logical thinking analysis through the Euclidean geometry. Global Journal of Pure and Applied Mathematics, 12(1), 1069-1075.

Jasečková, G., \& Krivoňáková, N. (2016). Logic as a key tool in education. Proceedings of the 15th Conference on Applied Mathematics APLIMAT 2016; Bratislava; Slovakia; 2-4 February 2016, pp. 614-620

Kalmykova, Z. I. (1954). Processes of analysis and synthesis in solving arithmetic problems. News of APN RSFSR, 61, 206-232.

Kazachek, N. A., \& Epova, E. V. (2014). Formation of Pupils' Analytic-Synthetic Activity while Studying Algebra in the Context of Summer Professionally-Oriented School. Scholarly Notes of Transbaikal State University. Series Vocational Education, Theory and Methods of Teaching, 6, 145-151.

Koldunova I. D. (2015). Formation of subject competence on the theory of algorithms of students of higher pedagogical universities on the basis of analytic and synthetic activity. Bulletin of Tomsk State Pedagogical University, 11, 32-36.

Koldunova, I. D. (2015). Model of the development of the analytic-synthetic component of the thinking of future teachers of informatics in the teaching of the theory of algorithms. Bulletin of V.P. Astafiev KSP University, 1, 225-230.

Koldunova, I. D. (2015). The construction of analytical-synthetic problems in the theory of algorithms. Pedagogical Education in Russia, 4, 133-139.

Korostelev, A. A., \& Yarygin O.N. (2011). Competence approach: problems of terminology. Vector of Science of TSU. Series: Pedagogy, psychology, 2, 212-220.

Kozhabaev, K. G, \& Gabdullin, R. S. (2016).On the development of students' thinking in the process of teaching mathematics. Modern Science-Intensive Technologies, 5-3, 554-559.

Landa L. N. (1975). Ability to think. How can he teach? Moscow: Znanie.

Pivovarkin, O. K. (2015). Analytical and synthetic activity as a component of the educational and cognitive competence of students. Actual directions of scientific research of the XXI century: theory and practice, 9-1, 232236. doi:10.12737/15881

Pospelov, N. N. (1989). Formation of mental operations in high school students. Moscow: Pedagogika.

Ramirez-Benavides, K., \& Guerrero, L. A. (2015). MODEBOTS: Environment for Programming Robots for Children between the Ages of 4 and 6. Revista Iberoamericana de Tecnologiasdel Aprendizaje, 10(3), 152-159. doi:10.1109/RITA.2015.2452692

Sadi, Ö., \& Çakıroğlu, J. (2015). The effect of logical thinking ability and gender on science achievements and attitudes towards science. Croatian Journal of Education, 17(3), 97-115. doi:10.15516/cje.v17i0.881

Samarin, Y. A. (1962). Essays on the psychology of the mind: features of mental activity of schoolchildren. Moscow: Publishing house of the Academy of Pedagogical Sciences of the RSFSR.

Seyhan, H. G. (2015). The effects of problem solving applications on the development of science process skills, logical thinking skills and perception on problem solving ability in the science laboratory. Asia-Pacific Forum on Science Learning and Teaching, 16(2), article number 8.

Tokareva, L. I. (2014). Learning the students of analytical and synthetic activities in solving geometric problems. Mathematical Bulletin of Pedagogical Universities and Universities of the Volga-Vyatka region, 16, 278-283.

Vasil'eva, V. M., Arons, E. K., Fonsova, N. A., \& Shestova, I. A. (1988). The role of the time factor in human analytical-synthetic activities. Journal of the Institute of higher nervous activity named after I.P. Pavlov, 38(4), 601606.

Vygotsky, L. S. (1991). Pedagogical psychology. Edited by V. V. Davydov. Moscow: Pedagogika.

Walsh, A. (2002). Guide to Writing Learning Outcomes. Learning and Teaching Development Unit. Surrey: Kingston University, pp. 78-89.

While, R. W. (1959). Motivation reconsidered: The concept of competence. Psychological Review, 66, 297-333.

\section{http://www.ejmste.com}

